\title{
Normalized Quantitative PCR Measurements as Predictors for Ethene Formation at Sites Impacted with Chlorinated Ethenes
}

\author{
Katherine Clark $^{\dagger}$, Dora M. Taggart ${ }^{\dagger}$, Brett R. Baldwin ${ }^{\dagger}$, Kirsti M. Ritalahti ${ }^{\ddagger}, \S$, Robert W. \\ Murdoch $^{\ddagger}$, Janet K. Hatt ${ }^{\#}$, Frank E. Löffler ${ }^{\star}, \ddagger, \S, \|, \perp, \Phi$ \\ †Microbial Insights, Incorporated, 10515 Research Drive, Knoxville, Tennessee 37932, United \\ States \\ ‡Center for Environmental Biotechnology, University of Tennessee, Knoxville, Tennessee 37996, \\ United States \\ $\S$ Department of Microbiology, University of Tennessee, Knoxville, Tennessee 37996, United States \\ "Department of Civil and Environmental Engineering, University of Tennessee, Knoxville, \\ Tennessee 37996, United States \\ ${ }^{\perp}$ Department of Biosystems Engineering \& Soil Science, University of Tennessee, Knoxville, \\ Tennessee 37996, United States \\ \#School of Civil and Environmental Engineering, Atlanta, Georgia 30332-0512 \\ "Biosciences Division and Joint Institute for Biological Sciences (JIBS), Oak Ridge National \\ Laboratory, Oak Ridge Tennessee 37831, United States
}

\begin{abstract}
Quantitative PCR (qPCR) targeting Dehalococcoides mccartyi (Dhc) biomarker genes supports effective management at sites impacted with chlorinated ethenes. To establish correlations between $D h c$ biomarker gene abundances and ethene formation (i.e., detoxification), 859 groundwater samples representing 62 sites undergoing monitored natural attenuation or enhanced remediation were analyzed. Dhc 16S rRNA genes and the vinyl chloride (VC) reductive dehalogenase genes $b v c A$ and $v c r A$ were detected in $88 \%$ and $61 \%$ of samples, respectively, from wells with ethene. $D h c$ 16S rRNA, $b v c A$, vcrA, and tce $A$ (implicated in cometabolic reductive VC dechlorination) gene abundances all positively correlated with ethene formation. Significantly greater ethene concentrations were observed when Dhc 16S rRNA gene and VC RDase gene abundances exceeded $10^{7}$ and $10^{6}$ copies $\mathrm{L}^{-1}$, respectively, and when Dhc 16S rRNA- and $b v c A+v c r A$-tototal bacterial 16S rRNA gene ratios exceeded $0.1 \%$. Dhc $16 \mathrm{~S}$ rRNA gene-to- $v c r A / b v c A$ ratios near unity also indicated elevated ethene; however, no increased ethene was observed in 19 wells where $v c r A$ and/or $b v c A$ gene copy numbers exceeded $D h c$ cell numbers 10- to 10000 -fold.
\end{abstract}

\footnotetext{
“Corresponding Author Phone: (865) 974-4933; fax: (865) 974-4007; frank.loeffler@utk.edu. Supporting Information

The Supporting Information is available free of charge on the ACS Publications website at DOI: 10.1021/acs.est.8b04373. Breakdown of microbial and geochemical data for the 859 groundwater samples by treatment, Figure S1; and illustration of Dhc $16 \mathrm{~S}$ rRNA gene copy abundances by treatment, Figure S2 (PDF)

The authors declare no competing financial interest.
} 
Approximately one-third of samples with detectable ethene lacked $b v c A, v c r A$, and $t c e A$, suggesting that comprehensive understanding of $\mathrm{VC}$ detoxification biomarkers has not been achieved. Although the current biomarker suite is incomplete, the data analysis corroborates the value of the available Dhc DNA biomarkers for prognostic and diagnostic groundwater monitoring at sites impacted with chlorinated ethenes.

\section{Graphical Abstract}

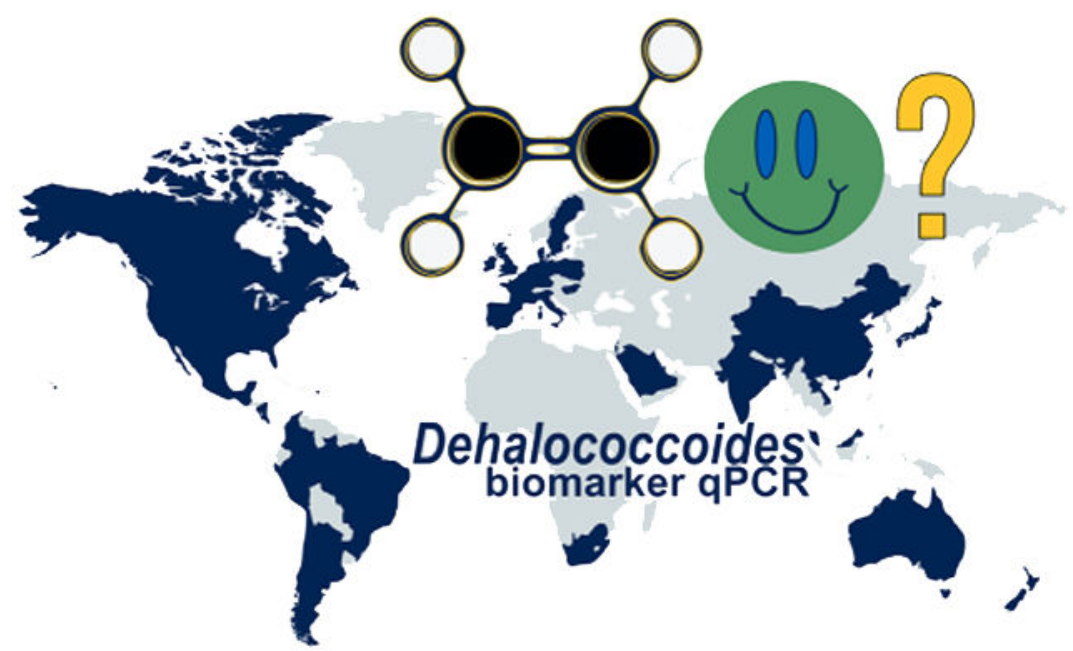

\section{INTRODUCTION}

Dehalococcoides mccartyi $(D h c)$ strains are adept at removing chlorine substituents from a wide variety of chlorinated priority contaminants while conserving energy for growth. ${ }^{1}$ In particular, the presence of $D h c$ has been linked to the reductive dechlorination of chlorinated ethenes to nontoxic ethene and inorganic chloride. ${ }^{2-5}$ Quantitative real-time PCR (qPCR) targeting $D h c$ reductive dehalogenase (RDase) and Dhc 16S rRNA genes is the tool of choice for assessment of monitored natural attenuation (MNA) and enhanced bioremediation. ${ }^{6-8}$ Detoxification of chlorinated ethenes at numerous contaminated sites occurs when $D h c$ abundances exceed $10^{7} D h c \mathrm{~L}^{-1}{ }^{4,7,9}$ Of the 444 distinct $D h c$ putative RDase proteins listed in the NCBI Identical Protein Groups database, PceA, TceA, PteA, $\mathrm{MbrA}$, and PcbA1, PcbA4, and PcbA5 have been linked to reductive dechlorination of tetrachloroethene (PCE) and/or trichloroethene (TCE). PceA and PteA dechlorinate PCE to TCE, ${ }^{10,11}$ and MbrA, PcbA1, PcbA4, and PcbA5 were reported to dechlorinate PCE and TCE to a mixture of cis-1,2-dichloroethene (cDCE) and trans-1,2-dichloroethene (tDCE). ${ }^{12,13} D h c$ strains harboring the $t c e A$ gene can use TCE, cDCE, and tDCE as respiratory electron acceptors but cannot grow with VC; however, $D h c$ strains harboring $t c e A$ have been implicated in cometabolic transformation of VC to ethene. ${ }^{14,15}$ The only Dhc RDases implicated in growth-linked reductive dechlorination of dichloroethenes to VC and to ethene are VcrA and BvcA. ${ }^{16-18}$ Of note, strain BAV1 harboring BvcA comet- abolizes TCE, and possibly PCE, in the presence of a growthsupporting electron acceptor (i.e., DCEs and VC). 18 
Molecular tools have become invaluable for monitoring processes of interest in environmental systems, and extracting DNA from groundwater has become routine laboratory practice. ${ }^{4} \mathrm{qPCR}$ has emerged as a mainstay technology to detect and quantify target genes in clinical and environmental samples. ${ }^{19-21}$ On the basis of the available $D h c$ genome information, Dhc RDase and 16S rRNA genes occur as single copy genes, ${ }^{22-24}$ and the application of both phylogenetic and functional gene-based qPCR measurements provides information about the abundance of $D h c$ strains carrying specific RDase genes capable of reductive dechlorination of different chlorinated ethenes. ${ }^{5,6,8,25}$ The analysis of these biomarker genes can be used to predict a plume's trajectory without treatment, establish the need for enhanced bioremediation treatment, and track progress during bioremediation applications. ${ }^{26,27}$ The value of $D h c$ biomarker gene analysis for in situ monitoring programs has been demonstrated and is commonly applied at sites slated for MNA or enhanced bioremediation treatment. ${ }^{4,7,8}$ To further validate the $D h c$ quantitative biomarker approach and establish correlations between qPCR data and reductive dechlorination, we performed an integrated analysis of biomarker gene abundances, contaminant concentrations and ethene formation in 859 groundwater samples representing 62 sites impacted with chlorinated ethenes undergoing physical/chemical treatment, MNA, or enhanced bioremediation (i.e., biostimulation or biostimulation combined with bioaugmentation).

\section{MATERIALS AND METHODS}

\section{Materials.}

The MO BIO PowerSoil kit (MO BIO Laboratories, Carlsbad, CA) was used to extract DNA from groundwater following previously described modifications and reagents for qPCR analysis were obtained from Life Technologies (Carlsbad, CA). ${ }^{6}$ Millipore Sterivex cartridges (SVGPL10RC) were used to collect biomass from groundwater. Chemicals for medium preparation were purchased from Fisher Scientific (Pittsburgh, PA) and SigmaAldrich (St. Louis, MO).

\section{Data Collection.}

Microbial Insights (MI, www.microbe.com) maintains an internal database of qPCR results of the abundances of 16S rRNA genes of microorganisms and functional genes (e.g., RDase genes) involved in biodegradation of common groundwater contaminants. At the time of manuscript preparation, the MI database contained site samples from across the U.S. and 33 countries around the world, including 27707 groundwater samples that had been analyzed for Dhc 16S rRNA genes. Of these groundwater samples, a subset of 859 samples that had associated geochemical data, including ethene, methane, and/or sulfate concentrations as well as concentrations of chlorinated ethenes, was used in the current study (Figure S1 of the Supporting Information, SI).

Of these 859 groundwater samples, 573 were collected from monitoring wells at sites undergoing MNA, 157 were from wells influenced by electron donor addition (biostimulation), and 73 were from wells in areas where biostimulation was applied in combination with bioaugmentation (i.e., injection of a Dhc-containing consortium). The 
remainder of the groundwater samples were collected from monitoring wells at sites undergoing treatment with zerovalent iron (37 samples), chemical oxidation (8 samples), or unspecified treatment (11 samples). Dissolved ethene and methane concentrations were available for 625 and 554 groundwater samples, respectively. Sulfate concentrations were reported for 685 groundwater samples, including 148 samples from monitoring wells at sites undergoing biostimulation or bioaugmentation. Detection limits were in the ranges of 2 to $10 \mathrm{mg} \mathrm{L}^{-1}$ for sulfate, 5 to $50 \mu \mathrm{g} \mathrm{L}^{-1}$ for dissolved methane, and 1 to $5 \mu \mathrm{g} \mathrm{L}^{-1}$ for dissolved ethene.

\section{Statistical Analysis and Data Processing.}

An analysis of variance (ANOVA) was performed to reveal significant differences in concentrations of ethene, sulfate, and methane (dependent variables) with $D h c$ and RDase gene abundances as categorical predictors. Due to non-normal distributions and/or nonequal variances, the nonparametric method Kruskal-Wallis ANOVA was used to determine significant differences among groups based on ranks or medians. ${ }^{28,29}$ The Kruskal-Wallis test is an alternative to parametric one-way ANOVA and used to test the null hypothesis that different samples in the comparison were drawn from distributions with the same median. As an example, in Figure 1A the Kruskal-Wallis test was used to determine whether the mean ranks of ethene concentrations were the same for different $D h c$ abundance groups. For some statistical analyses, such as the calculation of Spearman rank order coefficients $(\rho)$ between the logarithm of $D h c$ and RDase gene abundances and chlorinated ethene concentrations, the data set was constrained to samples in which $D h c$ abundances exceeded the practical quantitation limit (typically $10^{2} 16 \mathrm{~S}$ rRNA gene copies $\mathrm{L}^{-1}$ ). Kruskal-Wallis ANOVA with sulfate and methane as the dependent variables and log Dhc 16S rRNA gene copies as the categorical predictor was limited to groundwater samples from locations undergoing biostimulation alone or combined with bioaugmentation. This approach focused the analysis on samples where electron donor limitation was unlikely, thereby isolating geochemical conditions and providing the opportunity to assess the impact of methanogenesis as the primary variable impacting $D h c$ biomarker gene abundances. Sample sizes and selection criteria for each analysis are included in the respective figure legends. The strengths of Spearman rank order coefficients were qualified as follows: $\rho<0.2$ was very weak; $\rho=0.2-0.39$ was weak; $\rho=0.4-0.59$ was moderate; $\rho=0.6-0.79$ was strong; $\rho$ $=0.8-1.0$ was very strong. All statistical analyses were performed using Statistica v12.0 (StatSoft, Inc., Tulsa, OK) with $a=0.05$ (95\% confidence level) unless otherwise noted.

\section{Groundwater Sampling, DNA Extraction and Quantitative Real-Time PCR (qPCR).}

Groundwater collected by low-flow pumping techniques was shipped to MI in 1-L containers on ice as previously described, ${ }^{30}$ or alternatively biomass was collected on site using Sterivex cartridges. ${ }^{4}$ DNA from groundwater samples and Sterivex cartridges was extracted as described. ${ }^{4}$ Protocols to prepare qPCR calibration curves and quantify total bacterial 16S rRNA genes, $D h c$ 16S rRNA genes, and the RDase genes $t c e A, b v c A$, and vcrA followed established procedures. ${ }^{4,6}$ 


\section{Quality Assurance.}

Field samples were immediately placed in a cooler with blue ice, shipped overnight to the analytical laboratory, and DNA extractions were performed upon receipt. DNA quantification using an UV/vis spectrophotometer was not possible for the majority of DNA samples due to low A260 nm readings. For qPCR, eight-point standard curves were generated with 10-fold dilutions of linearized plasmid DNA carrying single copies of the respective target genes at $1 \mathrm{ng} \mu \mathrm{L}^{-1}$ starting concentration, ${ }^{6}$ and accompanied each qPCR plate. ${ }^{20}$ Undiluted and 1:10 diluted DNA samples were analyzed to achieve two data sets for each sample and to recognize PCR inhibition. ${ }^{4}$ Nonexponential fluorescence signal increase or other than a 10-fold difference in target gene enumeration in the dilutions of template DNA indicated PCR inhibition, ${ }^{31}$ and those reactions were not included in the analysis.

\section{RESULTS}

\section{Dhc Biomarker Gene and RDase Gene Detection Frequencies.}

Dhc 16S rRNA genes were detected in 88\% (755) of the 859 groundwater samples analyzed. Of those 755 groundwater samples with detectable (i.e., $>10^{2}$ gene copies $\mathrm{L}^{-1}$ ) Dhc $16 \mathrm{~S}$ rRNA genes, 625 had also been analyzed for $t c e A, b v c A$ and $v c r A$, with detection frequencies of $47 \%, 32 \%$, and $42 \%$, respectively. In 301 groundwater samples with quantifiable (i.e., $>5 \times 10^{2} 16 \mathrm{~S}$ rRNA gene copies $\mathrm{L}^{-1}$ ) $D h c$ and with at least one VC RDase gene detected, both $b v c A$ and $v c r A$ were present in $52 \%$ (156) of samples. In this subset of 301 groundwater samples, bvcA, but not $v c r A$, was detected in 13\% (40) and $v c r A$, but not $b v c A$, was detected in 35\% (105) of samples. Overall, the high Dhc 16S rRNA gene and RDase gene detection frequencies demonstrate that $D h c$ are commonly present in chlorinated solvent-impacted aquifers although their abundance may be low (i.e., $<10^{3} 16 \mathrm{~S}$ rRNA genes $\mathrm{L}^{-1}$ ).

\section{Correlation of Dhc Biomarker Gene Abundances with Concentrations of Chlorinated Ethenes and Ethene.}

Spearman rank order correlation coefficients were calculated between contaminant concentrations and the logarithm of quantifiable Dhc 16S rRNA gene and RDase gene abundances (Table 1). This analysis revealed that PCE concentrations were very weakly correlated with $t c e A$ and $v c r A$ gene abundances and not significantly correlated with $D h c$ 16S rRNA gene or $b v c A$ abundances. In contrast, TCE, cDCE, tDCE, VC, and ethene concentrations were all significantly positively correlated with $D h c 16 \mathrm{~S}$ rRNA, $t c e A, b v c A$ or vcrA gene abundances. Correlations between TCE concentrations and Dhc 16S rRNA gene and RDase gene abundances were weak. For cDCE, correlations with Dhc 16S rRNA, tce $A$, and $v c r A$ genes were moderate while the correlation with $b v c A$ was weak. A strong correlation was noted between $\mathrm{VC}$ and tce A gene abundance, and moderate correlations were observed with Dhc 16S rRNA and vcrA gene abundances. The correlation between VC and $b v c A$ was relatively weak. Ethene concentration was moderately correlated with tceA gene abundance. While weak, ethene concentrations positively correlated with the abundances of $D h c$ and both VC RDase genes. 


\section{Kruskal-Wallis ANOVA with Dhc 16S rRNA Gene and RDase Gene Abundances and Ethene Concentrations.}

Dissolved ethene, an indicator for detoxification, was analyzed in 625 and detected in 237 groundwater samples. Dhc was present in $87 \%$ (207) of the 237 samples with detectable ethene. The $b v c A$ and/or $v c r A$ genes or the $t c e A$ gene were present in $61 \%$ (107 out of 175) and $50 \%$ ( 87 out of 175), respectively, of samples where RDase genes were analyzed and ethene was detected. Kruskal-Wallis ANOVA was performed to determine the minimum $D h c$ and RDase gene abundances that correlated with elevated ethene concentrations. At Dhc abundances greater than $10^{7} 16 \mathrm{~S}$ rRNA gene copies $\mathrm{L}^{-1}$, the mean rank of ethene concentrations was significantly higher than observed at lower Dhc abundances (Figure 1A, $p$ values $<0.009)$. The mean rank of ethene concentrations was significantly higher when the sum of $b v c A+v c r A$ gene abundances was greater than $10^{6}$ copies $\mathrm{L}^{-1}$ (Figure $1 \mathrm{~B}, p$ values $<0.004)$.

Ethene concentrations noticeably increased when Dhc 16S rRNA gene copies were on the order of $0.1-1 \%$ of total bacterial $16 \mathrm{~S}$ rRNA gene copies. Statistically, the mean rank of ethene concentrations was significantly greater in groundwater samples with $D h c$ greater than $1 \%$ of total bacterial $16 \mathrm{~S}$ rRNA gene copies (Figure $2 \mathrm{~A}, p$ values $<0.002$ ). The overall variability in bacterial 16S rRNA gene abundances was low based on the standard deviation (1.03) and semi-interquartile range (0.59) of the logarithm of bacterial 16S rRNA gene copies. Thus, the ratio of Dhc-to-bacterial 16S rRNA gene copies could serve as a means for evaluating the potential for complete reductive dechlorination. At $a=0.10$, the mean rank of ethene concentrations was significantly greater in groundwater samples when $b v c A+v c r A$ gene copies were greater than $0.1 \%$ of total bacterial $16 \mathrm{~S}$ rRNA gene copies (Figure 2B).

\section{Ethene Detection in Groundwater Samples with Low Dhc Abundance.}

Out of 237 groundwater samples with measurable ethene, 30 samples (21 from MNA and nine from biostimulation sites) had fewer than $10^{2} 16 \mathrm{~S}$ rRNA gene copies $\mathrm{L}^{-1}$ and $t c e A$, $v c r A$, and $b v c A$ (with one exception) genes were not detected. The average total concentrations of chlorinated ethene exceeded $6700 \mu \mathrm{g} \mathrm{L}^{-1}$ in 27 samples, and only three samples had average total concentrations of less than $50 \mu \mathrm{g} \mathrm{L}-1$. Of these 30 samples, only five had reported ethene concentrations of greater than $5 \mu \mathrm{g} \mathrm{L}^{-1}$. One of these samples was collected from a site where zerovalent iron (ZVI) treatment had been implemented, suggesting that abiotic degradation may have contributed to ethene production. In addition, three of the five samples were collected from sites where adjacent sampling locations showed $D h c$ abundances greater than $10^{6} 16 \mathrm{~S}$ rRNA gene copies $\mathrm{L}^{-1}$. Thus, ethene detection in wells with low $D h c$ abundances at these three sites may have been the result of advective transport of dissolved ethene from upgradient areas with active reductive dechlorination to ethene.

\section{Lack of Ethene Detection in Groundwater Samples with High Dhc Abundance.}

Significantly higher ethene concentrations were detected in $87 \%$ (62 samples) of the 71 samples with $D h c$ abundances exceeding $10^{7}$ copies $\mathrm{L}^{-1}$ (Figure $1 \mathrm{~A}, p$ values $<0.009$ ). Of the remaining nine samples with high $D h c$ but no observed ethene, four (three from biostimulation sites and one from an MNA site) had VC RDase genes greater than $10^{5}$ 
copies $\mathrm{L}^{-1}$. In these cases, PCE, TCE, or DCE isomers were the predominant chlorinated ethenes $\left(0.75<X_{\mathrm{PCE}}+X_{\mathrm{TCE}}+X_{\mathrm{DCE}}<0.96\right)$; and for three of these four samples, VC concentrations were below $5 \mu \mathrm{g} \mathrm{L}^{-1}$. With high $D h c$ abundances and detection of VC RDase genes at $10^{5}$ copies $\mathrm{L}^{-1}$, ethene would have likely been detected in subsequent groundwater monitoring events as reductive dechlorination proceeded. In the remaining five samples (all MNA) with high $D h c$ but no ethene, the total VC RDase gene abundances (i.e., $b v c A+$ $v c r A$ ) were less than $10^{4}$ copies $\mathrm{L}^{-1}$, but $t c e A$ abundances ranged from $10^{4}$ to $10^{6}$ copies $\mathrm{L}$

${ }^{-1}$. As shown in Figure 1B, ethene concentrations generally increased when VC RDase gene abundances exceeded $10^{5}$ gene copies $\mathrm{L}^{-1}$ and were significantly higher at $10^{6} \mathrm{VC}$ RDase gene copies $\mathrm{L}^{-1}$. Thus, a lower abundance of $D h c$ strains harboring VC RDase genes may explain limited ethene formation in these samples.

\section{Influence of Treatment Approach on Dhc and RDase Gene Abundances.}

Kruskal-Wallis ANOVA was performed to identify any significant differences in the abundances of $D h c$ and RDase genes between treatments (Table 2). When present at quantifiable abundances, $D h c$ 16S rRNA genes and $t c e A, b v c A$ and $v c r A$ genes were each significantly more abundant in samples influenced by bioaugmentation than with biostimulation alone. At biostimulation sites that received fermentable substrate (i.e., electron donor) addition(s), the Dhc 16S rRNA $\left(p<10^{-6}\right)$ and $t c e A(p<0.007)$ genes were significantly more abundant compared to MNA sites. In contrast, the $b v c A$ and $v c r A$ genes were not significantly more abundant in samples from biostimulation sites than MNA sites.

At bioaugmentation sites, the $D h c$ abundance met or exceeded the $10^{7}$ gene copies $\mathrm{L}^{-1}$ threshold for strong ethene formation in 59\% (43/73) of the samples, and the vcrA abundances exceeded the $10^{6}$ copies $\mathrm{L}^{-1}$ threshold in over $70 \%(52 / 73)$ of the samples (Figure S2). Ethene was analyzed and detected in 27 of the samples meeting the $D h c$ threshold. At biostimulation sites, the $D h c$ abundances met the $10^{7}$ gene copies $\mathrm{L}^{-1}$ threshold in 23\% (36/157) of the samples analyzed. Unfortunately, ethene was analyzed in only 9 of these 36 samples and was detected in six of them. VC RDase gene abundances exceeded $10^{6}$ gene copies $\mathrm{L}^{-1}$ in less than $10 \%$ of the samples from sites undergoing biostimulation or MNA treatment.

\section{Effect of Sulfate and Methane Concentrations on Dhc Abundances.}

The relatively low number of samples with desirable $D h c 16 \mathrm{~S}$ rRNA gene (i.e., $>10^{7}$ copies $\mathrm{L}^{-1}$ ) and VC RDase gene (i.e., $>10^{6}$ copies $\mathrm{L}^{-1}$ ) abundances from sites undergoing biostimulation and even bioaugmentation was surprising. A Kruskal-Wallis ANOVA on ranks was performed to examine the relationship between sulfate and methane concentrations and $D h c$ abundances for samples influenced by biostimulation and bioaugmentation. The mean ranks of dissolved sulfate concentrations were significantly lower in samples $(n=142)$ with $D h c$ abundances greater than $10^{5} 16 \mathrm{~S}$ rRNA gene copies L ${ }^{-1}$ (Figure 3A, $p$ values $<0.0001$ ) corresponding to a mean sulfate concentration of 20-25 $\mathrm{mg} \mathrm{L}^{-1}$. Dissolved sulfate was largely absent in groundwater samples undergoing biostimulation or bioaugmentation treatments at higher $D h c$ abundances. With the limited number of samples from biostimulation and bioaugmentation sites with available methane data $(n=43)$, statistical analysis with samples from all treatment approaches revealed that 
the mean rank of methane concentrations was significantly greater in samples with $D h c$ abundances greater than $10^{7} 16 \mathrm{~S}$ rRNA gene copies $\mathrm{L}^{-1}$. The average methane concentration was $\sim 1450 \mu \mathrm{g} \mathrm{L}^{-1}$ in samples with high $D h c$ abundances, whereas in samples with lower methane concentrations of $\sim 180 \mu \mathrm{g} \mathrm{L}^{-1}, 10^{2}$ or fewer Dhc $16 \mathrm{~S}$ rRNA gene copies $\mathrm{L}^{-1}$ were detected (Figure 3B, $p$ value $<0.0001$ ).

\section{RDase Gene Copies Exceeding Dhc 16S rRNA Gene Copies.}

In axenic Dhc cultures, RDase genes occur in a 1:1 ratio with the Dhc 16S rRNA gene (Figure 4A; solid line). Interestingly, the abundances of one or more RDase gene(s) exceeded Dhc 16S rRNA gene copies by at least an order of magnitude in 3\% (19) of the 626 groundwater samples with quantifiable Dhc 16S rRNA and RDase genes (Figure 4A; dashed line). The frequency, with which the $t c e A$, the $v c r A$, or the $b v c A$ RDase gene abundances substantially exceeded the $D h c$ cell numbers was similar (approximately 2\%), and often more than one RDase gene exceeded the $D h c$ cell number in a given sample. In the 13 samples where $b v c A$ gene copies were at least 10-fold greater than the $D h c$ abundance, tce $A$ and $v c r A$ also exceeded the $D h c$ numbers in six and 11 samples, respectively.

Regardless of how frequently RDase gene copies substantially exceeded the $D h c$ abundances, ethene production was not enhanced in samples exhibiting VC RDase genes abundances 10- to 10000 -fold higher than the Dhc 16S rRNA gene abundance (Figure 4B). Of note, in a few groundwater samples with $b v c A+v c r A / D h c 16 \mathrm{~S}$ rRNA gene ratio $<0.01$, substantial ethene concentrations were observed (Figure 4B). This observation suggests that yet to be discovered RDases contribute to $\mathrm{VC}$ to ethene reductive dechlorination.

\section{DISCUSSION}

A suite of remediation technologies is available to tackle cleanup at sites impacted with chlorinated solvents, particularly chlorinated ethenes. Bioremediation has emerged as a productive stand-alone remedial approach or is applied in combination with a physical or chemical treatment approach. ${ }^{32-35}$ At sites impacted with chlorinated ethenes, Dhc strains play key roles in catalyzing the reductive dechlorination and detoxification to environmentally benign ethene under anoxic conditions. ${ }^{1,5}$ A number of site-specific studies have demonstrated the value of Dhc biomarker-targeted site monitoring, (e.g., ${ }^{8,36,37}$ ) and the quantitative analysis of $D h c$ biomarker genes is commonly applied during site assessment and bioremediation monitoring regimes at sites impacted with chlorinated ethenes.

\section{Dhc Detection Frequency in Groundwater.}

When first discovered, Dhc was considered to have limited distribution due to its restricted lifestyle that hinges on hydrogen as electron donor and specific chloroorganic compounds as electron acceptors. ${ }^{2,5}$ The data analysis presented here demonstrated that $D h c$ are commonly present in contaminated aquifers (detected in 682 out of 786 [87\%] samples examined) without bioaugmentation treatment. This observation is consistent with an increasing number of studies reporting $16 \mathrm{~S}$ rRNA gene sequences representing organohalide-respiring Chloroflexi in environments not impacted by chlorinated solvent contamination. ${ }^{38,39}$ Apparently, Dhc strains are members of microbial communities in pristine environments where naturally occurring organohalogens support their energy metabolism. Since many Dhc 
strains use chlorinated ethenes as respiratory electron acceptors, the high detection frequency of $D h c$ in groundwater impacted with chlorinated ethenes is not surprising.

\section{Correlation between Ethene Formation and Dhc Biomarker Gene Abundances.}

The complete dechlorination of chlorinated ethenes generally coincided with greater abundances of the Dhc 16S rRNA genes and VC RDase genes. The observed threshold Dhc abundance of $10^{7} 16 \mathrm{~S}$ rRNA gene copies $\mathrm{L}^{-1}$ for significantly greater ethene production (Figure 1A) is consistent with previous reports that suggested an abundance of $10^{7} \mathrm{Dhc}$ cells $\mathrm{L}^{-1}$ could be used as a screening criterion for generally useful rates of reductive dechlorination. ${ }^{4,9}$ To date, $v c r A$ and $b v c A$ are the only known $D h c$ genes that encode for RDases with confirmed VC reductive dechlorination activity. Remarkably, in 40\% (68 out of 175) of samples with confirmed presence of ethene, the known $D h c$ VC RDase genes $b v c A$ and $v c r A$ were not detected. The $t c e A$ gene was not detected in $34 \%$ (60 out of 175) of the samples indicating that cometabolic transformation of $\mathrm{VC}$ to ethene by TceA cannot explain ethene formation. Possible explanations for the detection of ethene in samples where the known VC RDase genes were absent include advective transport from zones where complete reductive dechlorination to ethene occurred, abiotic transformation reactions, ${ }^{14}$ or the presence of yet-to-be-identified VC RDases.

\section{Evidence for Additional VC RDases and other Bacteria Contributing to VC Reductive Dechlorination.}

In $3 \%$ (6 out of 175) of groundwater samples with ethene formation, the $D h c$ abundances exceeded $10^{7} 16 \mathrm{~S}$ rRNA gene copies $\mathrm{L}^{-1}$ but the VC RDase gene copies were orders of magnitude lower ( $\triangle 10^{4}$ copies $\mathrm{L}^{-1}$ ). The $t c e A$ gene implicated in cometabolic VC transformation to ethene $\mathrm{e}^{2,40}$ was detected in half of the samples, indicating that cometabolic $\mathrm{VC}$ transformation to ethene could not explain ethene formation. Because the known $D h c$ are obligate organohalide-respiring bacteria, this observation suggests that $D h c$ not possessing the VC RDases $b v c A$ and $v c r A$ thrive in aquifers impacted with chlorinated ethenes and contribute to ethene formation. Since the first report linking $D h c$ to the complete reductive dechlorination of chlorinated ethenes, ${ }^{2}$ the reductive dechlorination to environmentally benign ethene has been solely attributed to certain $D h c$ strains. This dogma is being challenged by a recent report demonstrating that Candidatus Dehalogenimonas etheniformans harboring a novel VC RDase, cerA, dechlorinates TCE to ethene. ${ }^{41}$ Apparently, the diversity of organisms and genes involved in $\mathrm{VC}$ reductive dechlorination exceeds the known $D h c$ strains carrying $v c r A$ or $b v c A$, suggesting that the current diagnostic and prognostic PCR monitoring tools do not provide comprehensive information. Therefore, efforts to enrich and isolate organisms that utilize toxic chlorinated alkanes and alkenes as growth substrates should not be abandoned; however, innovative cultivation approaches are needed because the contemporary enrichment and isolation approaches have not expanded the taxonomic diversity of anaerobic VC dechlorinators.

These observations further suggest that the currently available bioaugmentation consortia do not take advantage of the existing genetic diversity of organisms that contribute to anaerobic VC detoxification. The commercially available bioaugmentation consortia are produced with PCE or TCE provided as an electron acceptor and contain predominantly Dhc strains 
harboring $v c r A$. Not surprisingly, $v c r A$ was generally much more abundant than $b v c A$ at bioaugmentation sites. Dhc strains that possess $b v c A$ rely on DCEs and VC as electron acceptors, as does $D h c$ strain BAV1, an isolate that can cometabolize but not conserve energy from PCE or TCE reductive dechlorination to CDCE. $3,5,17,23$ Dhc strains that harbor both the $b v c A$ and $v c r A$ genes have not been found, and $D h c$ strains with the $v c r A$ genotype outcompete $D h c$ harboring $b v c A$ in bioaugmentation consortia fed with TCE as a growth substrate and possibly at sites with PCE and TCE as the primary contaminants. 8,42,43

In addition to a weak positive correlation with ethene formation, elevated numbers of $b v c A$ were found at MNA sites where tDCE and VC were the predominant contaminants. No correlation was observed between tDCE and the vcrA gene, although enzyme assays have suggested that $v c r A$ of $D h c$ strain VS is able to dechlorinate tDCE; however, this activity has not been demonstrated in vivo. ${ }^{16}$ Dhc strain GT, which carries the vcrA gene, failed to grow with $\mathrm{tDCE}$ as an energy source ${ }^{1}$ lending credence to the notion that $\mathrm{tDCE}$ is a substrate for $D h c$ strains with $b v c A$ but not for those carrying $v c r A$.

\section{Value of Relative Abundance Ratios Based on Quantitative qPCR Data.}

All samples in this study were processed using the same protocols for sample handling, DNA extraction, and qPCR; however, no EPA-approved standard protocols exist. A systematic investigation of errors that can affect qPCR data recommended standard operating procedures, ${ }^{44}$ and methodologies to minimize operator-induced biases are available. ${ }^{45,46}$ Still, qPCR data for the same sample can differ between laboratories due to laboratory-specific procedures. Using relative abundance ratios like the ratio of $D h c$ to total bacterial 16S rRNA gene copies could circumvent the potential impacts of procedural differences. In the current study, ethene concentrations were noticeably higher when ratios of Dhc 16S rRNA genes to total bacterial 16S rRNA genes were greater than $0.1 \%$ and were significantly greater when ratios of $D h c$ to total bacterial $16 \mathrm{~S}$ rRNA genes were at least $1 \%$ (Figure 2A). Likewise, ethene concentrations were higher in samples where the ratio of the sum of VC RDase genes $b v c A$ and $v c r A$ to total bacterial 16S rRNA genes was at least $0.1 \%$ (Figure 2B). The frequencies of ethene detection at threshold levels or higher based on absolute abundance of Dhc $16 \mathrm{~S}$ rRNA genes ( $\geq 10^{7}$ copies $\mathrm{L}^{-1}$ ), absolute VC RDase gene abundance ( $\geq 10^{6}$ copies $\mathrm{L}^{-1}$ ), and ratios of $D h c$ to total bacterial 16S rRNA gene copies ( $\searrow 0.1 \%$ ) were similar $(87 \%, 78 \%$, and $82 \%$, respectively) suggesting the abundance ratios based on qPCR data provide meaningful information.

Relative abundance information can also be obtained using 16S rRNA gene amplicon sequencing, a common approach to survey bacterial community structure, ${ }^{47}$ or shotgun metagenomics, which avoids amplification altogether. In contrast to qPCR, amplicon sequencing does not provide absolute quantitative information, ${ }^{48}$ and absolute quantification in metagenomics is challenging and has yet to be established. ${ }^{49}$ Further, by nature of the polymerase chain reaction, qPCR is at least 1 order of magnitude more sensitive than current shotgun metagenomics approaches. While deeper sequencing can improve sensitivity, the cost for sequencing and analysis increase substantially. In summary, a qPCR strategy offers the required sensitivity, sufficient throughput, and generates absolute quantitative data that are directly comparable between samples collected over time and from different sites. 


\section{VC RDase Genes Outnumber Dehalococcoides 16S rRNA Genes.}

An interesting observation was that the gene copy numbers of a single, two or all three RDase genes (i.e., $t c e A, v c r A$, and $b v c A$ ) exceeded the total $D h c$ cell abundance 10- to 10 000-fold in 19 samples (Figure 4B). Consistent with this observation, a 100-fold excess of vcrA genes relative to the total $D h c$ abundance was seen at 11 sites impacted with chlorinated ethenes in The Netherlands and one aquifer in the U.K. ${ }^{50}$ Further, a 6.5 fold higher $v c r A$ gene $\left(9.96 \times 10^{11} \mathrm{~L}^{-1}\right)$ than $D h c 16 \mathrm{~S}$ rRNA gene $\left(1.54 \times 10^{11} \mathrm{~L}^{-1}\right)$ abundance was reported in a TCE-dechlorinating bioreactor. ${ }^{51}$ While two- or three-fold differences in RDase to Dhc cell abundances could be the result of qPCR variation or due to gene duplication within a dominant $D h c$ strain, neither explains the up to 10000 -fold difference in gene enumeration (Figure 4B). In the 859 sample survey reported here, the greatest folddifferences between the Dhc 16S rRNA gene and RDase gene copy numbers occurred when $D h c$ cells were present in low abundances (i.e., in the range of $10^{3}$ to $10^{4}$ cells $\mathrm{L}^{-1}$ ) and mostly at MNA sites. Dehalogenimonas, another genus within the family Dehalococcoidia, has been implicated in reductive dechlorination of chlorinated alkanes, ${ }^{52-54} \mathrm{TCE},{ }^{41}$ and tDCE ${ }^{55}$ Horizontal gene transfer between Dhc and Dehalogenimonas can occur; ${ }^{56}$ however, there is no evidence to date for the presence of $b v c A$ and $v c r A$ in Dehalogenimonas genomes. Since the overabundance of RDase genes did not correlate with heightened dechlorination activity (i.e., ethene formation), an external RDase gene reservoir must be considered. An intriguing possibility is the occurrence of these RDase genes on phage genomes ${ }^{57}$ or as components of gene transfer agents, ${ }^{58}$ which is an exciting aspect of Dhc biology that warrants exploration.

\section{Effect of Treatment Strategies and Sulfate Concentrations on Dhc Abundances.}

Enhanced anaerobic bioremediation is an established treatment at sites impacted by chlorinated ethenes. Ethene production was observed in nearly $70 \%$ of the groundwater samples obtained from sites undergoing biostimulation alone or combined with bioaugmentation. At a number of sites undergoing enhanced anaerobic bioremediation, in situ ethene formation occurred below the $10^{7}$ Dhc $16 \mathrm{~S}$ rRNA gene copies $\mathrm{L}^{-1}$ threshold for sustaining generally useful rates of reductive dechlorination. ${ }^{4,9}$ The percentage of sites experiencing biostimulation treatment and reaching the $10^{7}$ Dhc $16 \mathrm{~S}$ rRNA gene copies $\mathrm{L}^{-1}$ threshold was $23 \%$ (36 out of 157), which is substantially lower than what is generally observed at field sites undergoing biostimulation treatment. ${ }^{59}$

On the basis of the data set available for this study, Dhc biomarkers were detected in the majority of groundwater samples from MNA sites $(86 \%, 495 / 573)$ suggesting that lower than desired $D h c$ abundances after biostimulation were not due to a lack of indigenous $D h c$. A recent case study reported significantly greater $D h c$ abundances when sulfate concentrations were below $50 \mathrm{mg} \mathrm{L}^{-160}$ and sulfate concentrations below $20 \mathrm{mg} \mathrm{L}^{-1}$ have been considered favorable to reductive dechlorination. ${ }^{61}$ The analysis of 685 samples with reported sulfate concentrations revealed that high $D h c$ abundances correlated with sulfate depletion (Figure 3A) and also with substantial methane generation (Figure 3B). For samples collected at biostimulation sites, sulfate concentrations were less than $20 \mathrm{mg} \mathrm{L}^{-1}$ in $64 \%$ (91 of 142) of samples, and methane concentrations exceeded $50 \mu \mathrm{g} \mathrm{L}^{-1}$ in $12 \%$ (5 of 43) of samples from biostimulation sites. Overall, the findings demonstrate the value of 
biostimulation combined with bioaugmentation or biostimulation alone to establish generally useful rates of reductive dechlorination, but also underscore the role of proper implementation to achieve favorable geochemical conditions for successful bioremediation.

\section{Database Limitations and Opportunities.}

The integrated analysis of microbiological, geochemical, physical, hydrological, etc. data collected from chlorinated solvent-impacted aquifers can unravel unrecognized correlations and reveal new insights into the reductive dechlorination process. Although the current MI database contains qPCR data from more than 30000 groundwater samples, associated site information is often incomplete, and only a subset of the data could be included in the analysis. A recent study demonstrated the value of machine learning-based data mining approaches to predict in situ detoxification potential of chlorinated ethenes, but highlighted the issue of data quality, completeness and accessibility. ${ }^{62}$ The authors of this prior study emphasized the value of a curated, open-access, up-to-date and comprehensive collection of biogeochemical groundwater monitoring data. ${ }^{62}$ The analyses performed in the current study were also limited to a subset of data included in the MI database, and three main issues were recognized: First, site-specific data are generated by different (commercial) laboratories and information is generally not recorded in a single depository. Second, public data access should not infringe on privacy rights, that is, the identity of a site under litigation cannot be released until a settlement has been reached. Third, inconsistent monitoring schedules and parameter sets, and a lack of standardized sampling protocols hamper integrated data analysis. Thus, building a systematic, comprehensive and open-access database that combines microbiological, geochemical, physical and hydrogeological aquifer/plume data, as well as information about treatment, should be a high priority. A number of U.S. states have implemented online data management systems for impacted sites (e.g., Geotracker; https://geotracker.waterboards.ca.gov), and a mechanism for data reporting in an openaccess repository is available. What is currently lacking is a guidance document that provides information about the parameters analyzed and the frequency (i.e., time windows) of sample collection, so that the efforts generate the information necessary for productive, site-specific decision making. As a next step, remediation and regulatory communities should partner to include microbial information in established (public) repositories and develop mechanisms for data curation, retrieval and analysis. Such a resource will enable fundamental discoveries about the reductive dechlorination process and can be a pillar for efforts aimed at developing predictive understanding about the trajectory of a chlorinated solvent plume under different treatment scenarios.

\section{Implications for bioremediation practice.}

The integrated data analysis reported here highlights the value of $D h c$ biomarker gene enumeration, and further demonstrates that ratios of $D h c$ to total bacterial 16S rRNA genes and of $b v c A+v c r A$ to total bacterial $16 \mathrm{~S}$ rRNA genes exceeding $0.1 \%$, and a ratio of $v c r A$ $+b v c A$ to $D h c 16 \mathrm{~S}$ tRNA genes near unity are useful normalized, measurable parameters for predicting detoxification (i.e., ethene formation) at sites impacted with chlorinated ethenes where $D h c$ are key dechlorinators. Thus, qPCR monitoring at sites impacted with chlorinated ethenes should include 16S rRNA genes of relevant dechlorinators (i.e., Dhc), key RDase genes such as $t c e A, v c r A$, and $b v c A$ and general primers quantifying total 
bacterial 16S rRNA genes, ideally in concert with the collection of relevant geochemical information, including contaminant and ethene concentration data. The analysis revealed ethene production in wells that lacked the known $v c r A$ or $b v c A$ VC RDase genes, demonstrating that comprehensive understanding of VC detoxification biomarkers has not yet been obtained. Consequently, complete reductive dechlorination to environmentally benign ethene can occur in the absence of the known VC RDase genes $v c r A$ and $b v c A$. The lack of open-access data management systems for groundwater monitoring data sets is a major hindrance, and remediation and regulatory communities should partner to include microbial information in established (public) repositories and develop mechanisms for data curation, retrieval and analysis.

\section{Supplementary Material}

Refer to Web version on PubMed Central for supplementary material.

\section{ACKNOWLEDGMENTS}

This research was supported by the U.S. Department of Defense's Strategic Environmental Research and Development Program (SERDP Project ER-2312), and by the Superfund Research Program under the National Institute of Environmental Health Sciences (award R01ES024294).

\section{REFERENCES}

(1). Löffler FE; Ritalahti KM; Zinder SH Dehalococcoides and reductive dechlorination of chlorinated solvents In SERDP ESTCP Environmental Remediation Technology; Stroo HF, Leeson A, Ward CH, Eds.; Springer: New York, NY, 2013; Vol. Bioaugmentation for Groundwater Remediation; pp 39-88.

(2). Maymó-Gatell X; Chien Y; Gossett JM; Zinder SH Isolation of a bacterium that reductively dechlorinates tetrachloroethene to ethene. Science 1997, 276 (5318), 1568-1571. [PubMed: 9171062]

(3). He J; Ritalahti KM; Yang K-L; Koenigsberg SS; Löffler FE Detoxification of vinyl chloride to ethene coupled to growth of an anaerobic bacterium. Nature 2003, 424, 62-65. [PubMed: 12840758]

(4). Ritalahti KM; Hatt JK; Lugmayr V; Henn K; Petrovskis EA; Ogles DM; Davis GA; Yeager CM; Lebrón CA; Löffler FE Comparing on-site to off-site biomass collection for Dehalococcoides biomarker gene quantification to predict in situ chlorinated ethene detoxification potential. Environ. Sci. Technol 2010, 44 (13), 5127-5133. [PubMed: 20545341]

(5). Löffler FE; Yan J; Ritalahti KM; Adrian L; Edwards EA; Konstantinidis KT; Müller JA; Fullerton H; Zinder S; Spormann AM Dehalococcoides mecartyi gen. nov., sp. nov., obligate organohaliderespiring anaerobic bacteria relevant to halogen cycling and bioremediation, belong to a novel bacterial class, Dehalococcoidia classis nov., order Dehalococcoidales ord. nov. and family Dehalococcoi-daceae fam. nov., within the phylum Chlorof lexi. Int. J. Syst. Evol. Microbiol 2013, 63 (2), 625-635. [PubMed: 22544797]

(6). Ritalahti KM; Amos BK; Sung Y; Wu Q; Koenigsberg SS; Löffler FE Quantitative PCR targeting 16S rRNA and reductive dehalogenase genes simultaneously monitors multiple Dehalococcoides strains. Appl. Environ. Microbiol 2006, 72 (4), 2765-2774. [PubMed: 16597981]

(7). Cupples AM Real-time PCR quantification of Dehalococcoides populations: methods and applications. J. Microbiol. Methods 2008, 72 (1), 1-11 [PubMed: 18077025]

(8). Lee PK; Macbeth TW; Sorenson KS Jr.; Deeb RA; Alvarez-Cohen L Quantifying genes and transcripts to assess the in situ physiology of Dehalococcoides spp. in a trichloroethenecontaminated groundwater site. Appl. Environ. Microbiol 2008, 74(9), 2728-2739. [PubMed: 18326677] 
(9). Lu X; Wilson JT; Kampbell DH Relationship between Dehalococcoides DNA in ground water and rates of reductive dechlorination at field scale. Water Res. 2006, 40 (16), 3131-3140. [PubMed: 16889813]

(10). Magnuson JK; Stern RV; Gossett JM; Zinder SH; Burris DR Reductive dechlorination of tetrachloroethene to ethene by a two-component enzyme pathway. Appl. Environ. Microbiol 1998, 64, 1270-1275. [PubMed: 10671186]

(11). Zhao S; Ding C; He J Genomic characterization of Dehalococcoides mccartyi strain 11a5 reveals a circular extrachromosomal genetic element and a new tetrachloroethene reductive dehalogenase gene. FEMS Microbiology Ecology 2016, 93 (4), fiw235-fiw235.

(12). Cheng D; He J Isolation and characterization of "Dehalococcoides" sp. strain MB, which dechlorinates tetrachloroethene to trans-1,2-dichloroethene. Appl. Environ. Microbiol 2009, 75 (18), 5910-5918. [PubMed: 19633106]

(13). Wang S; Chng KR; Wilm A; Zhao S; Yang K-L; Nagarajan N; He J Genomic characterization of three unique Dehalococcoides that respire on persistent polychlorinated biphenyls. Proc. Natl. Acad. Sci. U. S. A 2014, 111 (33), 12103-12108. [PubMed: 25028492]

(14). He YT; Wilson JT; Su C; Wilkin RT Review of abiotic degradation of chlorinated solvents by reactive iron minerals in aquifers. Groundwater Monit. Rem 2015, 35 (3), 57-75.

(15). Magnuson JK; Romine MF; Burris DR; Kingsley MT Trichloroethene reductive dehalogenase from Dehalococcoides ethenogenes: sequence of tce $A$ and substrate range characterization. Appl. Environ. Microbiol 2000, 66, 5141-5147. [PubMed: 11097881]

(16). Müller JA; Rosner BM; Von Abendroth G; Meshulam-Simon G; McCarty PL; Spormann AM Molecular identification of the catabolic vinyl chloride reductase from Dehalococcoides sp. strain VS and its environmental distribution. Appl. Environ. Microbiol2004, 70,4880-4888 [PubMed: 15294827]

(17). Krajmalnik-Brown R; Hölscher T; Thomson IN; Saunders FM; Ritalahti KM; Löffler FE Genetic identification of a putative vinyl chloride reductase in Dehalococcoides sp. strain BAV1. Appl. Environ. Microbiol 2004, 70 (10), 6347-6351. [PubMed: 15466590]

(18). Tang S; Chan WWM; Fletcher KE; Seifert J; Liang XM; Löffler FE; Edwards EA; Adrian L Functional characterization of reductive dehalogenases by using blue native polyacrylamide gel electrophoresis. Appl. Environ. Microbiol 2013, 79 (3), 974-981. [PubMed: 23204411]

(19). VanGuilder HD; Vrana KE; Freeman WM Twenty-five years of quantitative PCR for gene expression analysis. BioTechniques 2008, 44 (5), 619-626. [PubMed: 18474036]

(20). Bustin SA; Benes V; Garson JA; Hellemans J; Huggett J ; Kubista M; Mueller R; Nolan T; Pfaffl MW; Shipley GL; Vandesompele J; Wittwer CT The MIQE guidelines: minimum information for publication of quantitative real-time PCR experiments. Clin. Chem 2009, 55 (4), 611-622. [PubMed: 19246619]

(21). Smith CJ; Osborn AM Advantages and limitations of quantitative PCR (Q-PCR)-based approaches in microbial ecology. FEMS Microbiol. Ecol 2009, 67 (1), 6-20. [PubMed: 19120456]

(22). Kube M; Beck A; Zinder SH; Kuhl H; Reinhardt R; Adrian L Genome sequence of the chlorinated compound-respiring bacterium Dehalococcoides species strain CBDB1. Nat. Biotechnol 2005, 23, 1269-1273. [PubMed: 16116419]

(23). McMurdie PJ; Behrens SF; Müller JA; Goke J; Ritalahti KM; Wagner R; Goltsman E; Lapidus A; Holmes S; Löffler FE; Spormann AM Localized plasticity in the streamlined genomes of vinyl chloride respiring Dehalococcoides. PLoS Genet. 2009, 5 (11), e1000714. [PubMed: 19893622]

(24). Seshadri R; Adrian L; Fouts DE; Eisen JA; Phillippy AM; Methe BA; Ward NL; Nelson WC; Deboy RT; Khouri HM; Kolonay JF; Dodson RJ; Daugherty SC; Brinkac LM; Sullivan SA; Madupu R; Nelson KE; Kang KH; Impraim M; Tran K; Robinson JM; Forberger HA; Fraser CM; Zinder SH; Heidelberg JF; et al. Genome sequence of the PCE-dechlorinating bacterium Dehalococcoides ethenogenes. Science 2005, 307 (5706), 105-108. [PubMed: 15637277]

(25). Holmes VF; He J; Lee PKH; Alvarez-Cohen L Discrimination of multiple Dehalococcoides strains in a trichloroethene enrichment by quantification of their reductive dehalogenase genes. Appl. Environ. Microbiol 2006, 72 (9), 5877-5883. [PubMed: 16957207] 
(26). Lebrón CA; Petrovskis EA; Löffler FE; Henn K Guidance Protocol: Application of nucleic acidbased tools for monitoring monitored natural attenuation (MNA), biostimulation and bioaugmentation at chlorinated solvent sites Naval Facilities Engineering Command; 2011, ESTCP Project ER0518 NAVFAC ESC.

(27). Leeson A; Stroo HF; Johnson PC Groundwater remediation today and challenges and opportunities for the future. Groundwater 2013, 51 (2), 175-179.

(28). Kruskal WH; Wallis WA Use of ranks in one-criterion variance analysis. J. Am. Stat. Assoc 1952, 47 (260), 583-621.

(29). Day RW; Quinn GP Comparisons of treatments after an analysis of variance in ecology. Ecol. Monogr 1989, 59 (4), 433-463.

(30). Ritalahti KM; Hatt JK; Petrovskis E; Löffler FE Groundwater sampling for nucleic acid biomarker analysis In Handbook of Hydrocarbon and Lipid Microbiology; Timmis KN, Ed.; Springer: Berlin, 2010; pp 3407-3418.

(31). Nolan T; Hands RE; Bustin SA Quantification of mRNA using real-time RT-PCR Nat. Protoc 2006, 1 (3), 1559-1582. [PubMed: 17406449]

(32). Stroo HF; Ward CH In Situ Remediation of Chlorinated Solvent Plumes; Springer: New York, 2010.

(33). Stroo HF; Leeson A; Marqusee JA; Johnson PC; Ward CH; Kavanaugh MC; Sale TC; Newell CJ; Pennell KD; Lebron CA; Unger M Chlorinated ethene source remediation: lessons learned. Environ. Sci. Technol 2012, 46 (12), 6438-6447. [PubMed: 22558915]

(34). Stroo HF; Leeson A; Ward CH Bioaugmentation for Groundwater Remediation; Springer: New York, 2012.

(35). Adrian L; Löffler FE Organohalide-Respiring Bacteria; Springer: Berlin/Heidelberg, 2016.

(36). Major DW; McMaster ML; Cox EE; Edwards EA; Dworatzek SM; Hendrickson ER; Starr MG; Payne JA; Buonamici LW Field demonstration of successful bioaugmentation to achieve dechlorination of tetrachloroethene to ethene. Environ. Sci. Technol 2002, 36 (23), 5106-5116. [PubMed: 12523427]

(37). Lendvay JM; Löffler FE; Dollhopf M; Aiello MR; Daniels G; Fathepure BZ; Gebhard M; Heine R; Helton R; Shi J; Krajmalnik-Brown R; Major CL; Barcelona MJ; Petrovskis E ; Hickey R; Tiedje JM; Adriaens P Bioreactive barriers: A comparison of bioaugmentation and biostimulation for chlorinated solvent remediation. Environ. Sci. Technol 2003, 37 (7), 1422-1431.

(38). Krzmarzick MJ; Crary BB; Harding JJ; Oyerinde OO; Leri AC; Myneni SC; Novak PJ Natural niche for organohalide-respiring Chloroflexi. Appl Environ. Microbiol 2012, 78 (2), 393-401. [PubMed: 22101035]

(39). Atashgahi S; Häggblom MM; Smidt H Organohalide respiration in pristine environments: implications for the natural halogen cycle. Environ. Microbiol 2018, 20 (3), 934-948. [PubMed: 29215190]

(40). He J; Sung Y; Krajmalnik-Brown R; Ritalahti KM; Löffler FE Isolation and characterization of Dehalococcoides sp. strain FL2, a trichloroethene (TCE)- and 1,2-dichloroethene-respiring anaerobe. Environ. Microbiol 2005, 7, 1442-1450. [PubMed: 16104866]

(41). Yang Y; Higgins SA; Yan J; Simsir B; Chourey K; Iyer R; Hettich RL; Baldwin B; Ogles DM; Löffler FE Grape pomace compost harbors organohalide-respiring Dehalogenimonas species with novel reductive dehalogenase genes. ISME J. 2017, 11, 2767-2780. [PubMed: 28809851]

(42). Duhamel M; Mo K; Edwards EA Characterization of a highly enriched Dehalococcoidescontaining culture that grows on vinyl chloride and trichloroethene. Appl. Environ. Microbiol 2004, 70, 5538-5545. [PubMed: 15345442]

(43). Amos BK; Ritalahti KM; Cruz-Garcia C; Padilla-Crespo E; Löffler FE Oxygen effect on Dehalococcoides viability and biomarker quantification. Environ. Sci. Technol 2008, 42 (15), 5718-5726. [PubMed: 18754499]

(44). Lebrón CA; Dennis P; Acheson C; Barros N; Major DW; Petrovskis EA; Löffler FE; Ritalahti KM; Yeager CM; Edwards EA; Hatt JK; Ogles DM Standardized procedures for use of nucleic acid-based tools. 2014, SERDP Project ER-1561. 
(45). Hatt JK; Löffler FE Quantitative real-time PCR (qPCR) detection chemistries affect enumeration of the Dehalococcoides 16S rRNA gene in groundwater. J. Microbiol. Methods 2012, 88 (2), 263-270. [PubMed: 22200549]

(46). Hatt JK; Ritalahti KM; Ogles DM; Lebron CA; Löffler FE Design and application of an internal amplification control to improve Dehalococcoides mccartyi 16S rRNA gene enumeration by qPCR Environ. Sci. Technol 2013, 47 (19), 11131-11138.

(47). Clooney AG; Fouhy F; Sleator RD; O’ Driscoll A; Stanton C; Cotter PD; Claesson MJ Comparing apples and oranges?: Next generation sequencing and its impact on microbiome analysis. PLoS One 2016, 11 (2), e0148028. [PubMed: 26849217]

(48). Tsilimigras MCB; Fodor AA Compositional data analysis of the microbiome: fundamentals, tools, and challenges. Annals of Epidemiology 2016, 26 (5), 330-335. [PubMed: 27255738]

(49). Yang X; Noyes NR; Doster E; Martin JN; Linke LM; Magnuson RJ; Yang H; Geornaras I; Woerner DR; Jones KL; Ruiz J; Boucher C; Morley PS; Belk KE Use of metagenomic shotgun sequencing technology to detect foodborne pathogens within the microbiome of the beef production chain. Appl. Environ. Microbiol 2016, 82 (8), 2433-2443. [PubMed: 26873315]

(50). van der Zaan B; Hannes F; Hoekstra N; Rijnaarts H; de Vos WM; Smidt H; Gerritse J Correlation of Dehalococcoides spp. 16S rRNA and chloroethene reductive dehalogenase genes to different geochemical conditions in chloroethene-contaminated groundwater. Appl. Environ. Microbiol 2010, 76 (3), 843-850. [PubMed: 20008170]

(51). Ziv-El M; Delgado AG; Yao Y; Kang DW; Nelson KG; Halden RU; Krajmalnik-Brown R Development and characterization of DehaloR^2, a novel anaerobic microbial consortium performing rapid dechlorination of TCE to ethene. Appl. Microbiol. Biotechnol 2011, 92 (5), 1063-1071. [PubMed: 21667274]

(52). Moe WM; Yan J; Nobre MF; da Costa MS; Rainey FA Dehalogenimonas lykanthroporepellens gen. nov., sp. nov., a reductively dehalogenating bacterium isolated from chlorinated solventcontaminated groundwater. Int. J. Syst. Evol Microbiol 2009, 59 (11), 2692-2697. [PubMed: 19625421]

(53). Siddaramappa S; Challacombe JF; Delano SF; Green LD; Daligault H; Bruce D; Detter C; Tapia R; Han S; Goodwin L; Han J; Woyke T; Pitluck S; Pennacchio L; Nolan M; Land M; Chang YJ; Kyrpides NC; Ovchinnikova G; Hauser L; Lapidus A; Yan J; Bowman KS; da Costa MS; Rainey FA; Moe WM Complete genome sequence of Dehalogenimonas lykanthroporepellens type strain (BL-DC-9(T)) and comparison to "Dehalococcoides" strains. Stand. Genomic Sci 2012, 6 (2), 251-264. [PubMed: 22768368]

(54). Key TA; Bowman KS; Lee I; Chun J; Albuquerque L; da Costa MS; Rainey FA; Moe WM Dehalogenimonas formicexedens sp. nov., a chlorinated alkane-respiring bacterium isolated from contaminated groundwater. Int. J. Syst. Evol. Microbiol 2017, 67 (5), 1366-1373. [PubMed: 28126048]

(55). Manchester MJ; Hug LA; Zarek M; Zila A; Edwards EA Discovery of a trans-dichloroethenerespiring Dehalogenimonas species in the 1,1,2,2-tetrachloroethane-dechlorinating WBC-2 consortium. Appl. Environ. Microbiol 2012, 78 (15), 5280-5287. [PubMed: 22635995]

(56). Padilla-Crespo E; Yan J; Swift C; Wagner DD; Chourey K; Hettich RL; Ritalahti KM; Löffler FE Identification and environmental distribution of $\operatorname{dcp} A$, which encodes the reductive dehalogenase catalyzing the dichloroelimination of 1,2-dichloropropane to propene in organohalide-respiring Chloroflexi. Appl. Environ. Microbiol 2014, 80 (3), 808-818. [PubMed: 24242248]

(57). Ritalahti KM; Helton RR; Fletcher KE; Wommack KE; Löffler FE Preliminary evidence for phage-mediated horizontal gene transfer in Dehalococcoides. Presented at the 107th General Meeting of the American Society of Microbiology, Toronto, Canada, May 21-25, 20072007.

(58). Lang AS; Zhaxybayeva O; Beatty JT Gene transfer agents: phage-like elements of genetic exchange. Nat. Rev. Microbiol 2012, 10 (7), 472-482. [PubMed: 22683880]

(59). Tillotson JM; Borden RC Rate and extent of chlorinated ethene removal at 37 ERD sites. J. Environ. Eng 2017, 143 (8), 04017028.

(60). Baldwin BR; Taggart D; Chai Y; Wandor D; Biernacki A; Sublette KL; Wilson JT; WaleckaHutchison C; Coladonato C; Goodwin B Bioremediation management reduces mass discharge at a chlorinated DNAPL site. Groundwater Monit. Rem 2017, 37 (2), 58-70. 
(61). Morse JJ; Alleman BC; Gossett JM; Zinder SH; Fennell DE; Sewell GW; Vogel CM A Treatability Test for Evaluating the Potential Applicability of the Reductive Anaerobic Biological In Situ Treatment Technology (RABITT) to Remediate Chloroethenes; AFRL-ML-TY-TR-19984522; Air Force Research Laboratory: Arlington, VA, 1998; p 84.

(62). Lee J; Im J; Kim U; Löffler FE A data mining approach to predict In situ detoxification potential of chlorinated ethenes. Environ. Sci. Technol 2016, 50 (10), 5181-5188. [PubMed: 27116079] 

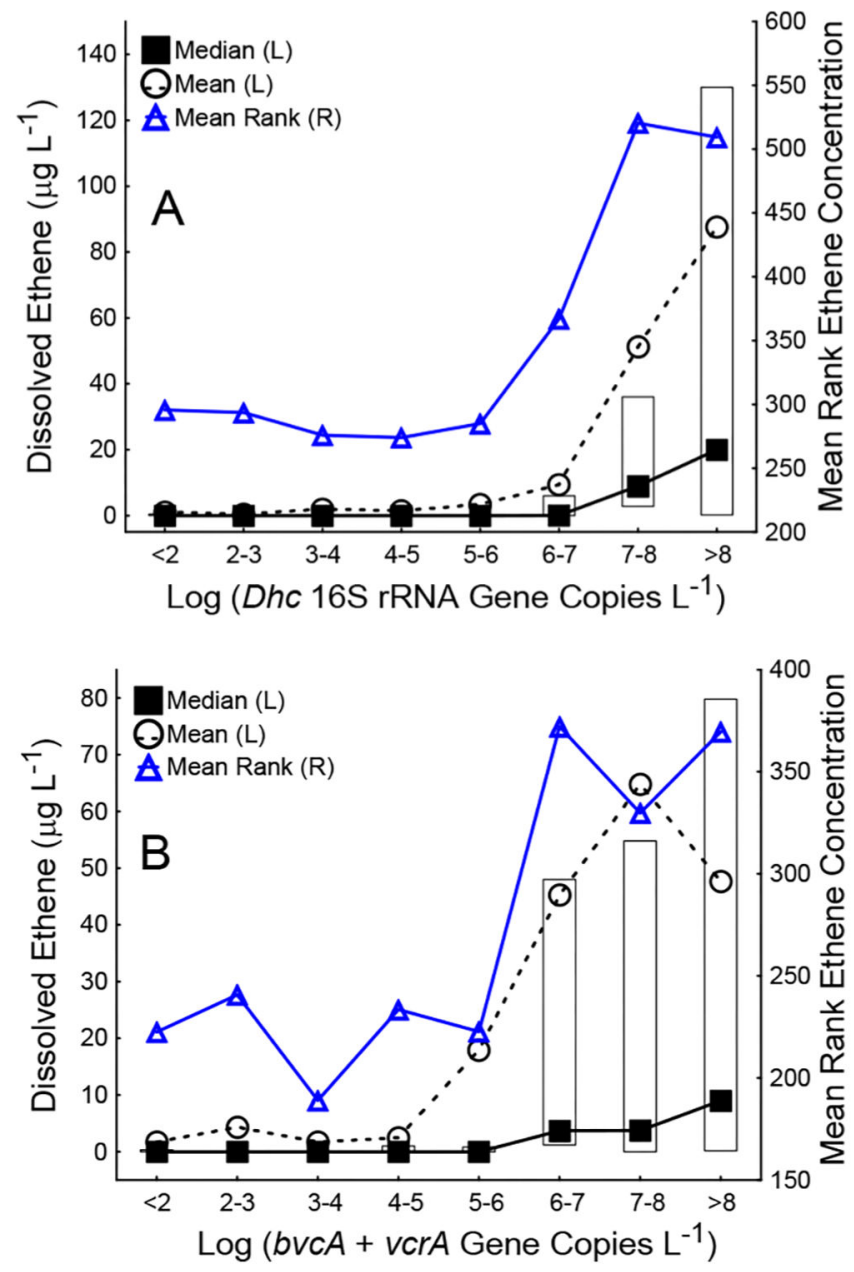

Figure 1.

Correlations between $D h c$ biomarker gene abundances and ethene concentrations. Ethene concentrations were significantly greater in samples with (A) Dhc 16S rRNA gene and (B) VC RDase gene abundances greater than $10^{7}$ copies $\mathrm{L}^{-1}$ and $10^{6}$ copies $\mathrm{L}^{-1}$, respectively. The Kruskal-Wallis H test, also known as the one-way ANOVA on ranks, was performed with ethene concentration as the dependent variable ( $y$ axis) and order of magnitude ranges of $\log D h c$ or $\log b v c A+v c r A$ abundance as the independent, categorical factor ( $x$ axis). For each category (e.g., $\log D h c 16 \mathrm{~S}$ rRNA gene copies $\mathrm{L}^{-1}<2$ ), the median, mean, and mean ranks of ethene concentrations are shown. Boxes represent the interquartile range. The top and the bottom of each box represent the $25^{\text {th }}$ and the $75^{\text {th }}$ percentiles, respectively. KruskalWallis tests $[\mathrm{H}(k-1, N)]$ for nonparametric one-way ANOVA indicated significant differences in mean ranks of ethene concentrations with $\log D h c$ abundance $[\mathrm{H}(7, N=625)=$ $141.3, p<0.05]$ and $\log b v c+v c r A$ abundance $[\mathrm{H}(7, N=479)=83.1, p<0.05]$ as the independent variables. 


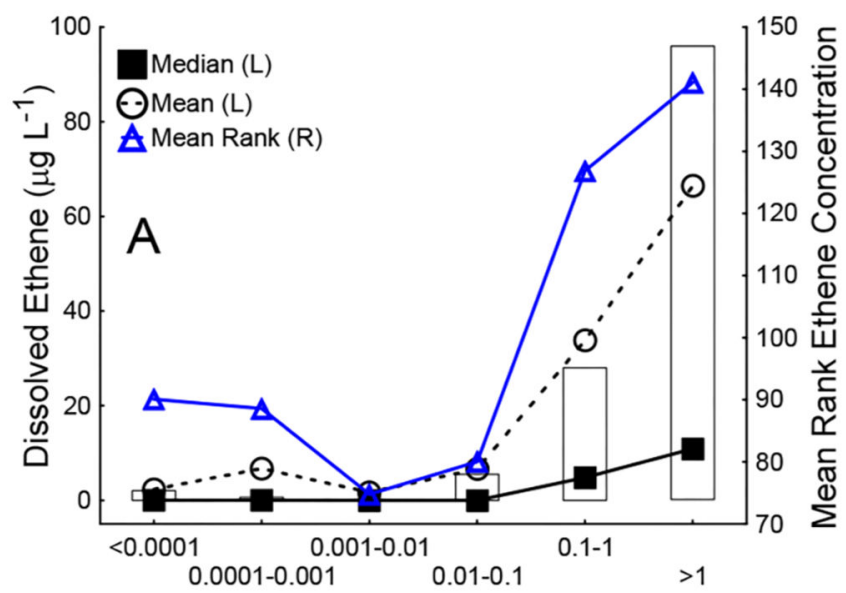

Dhc/Total Bacterial 16S rRNA Gene Copies (\%)

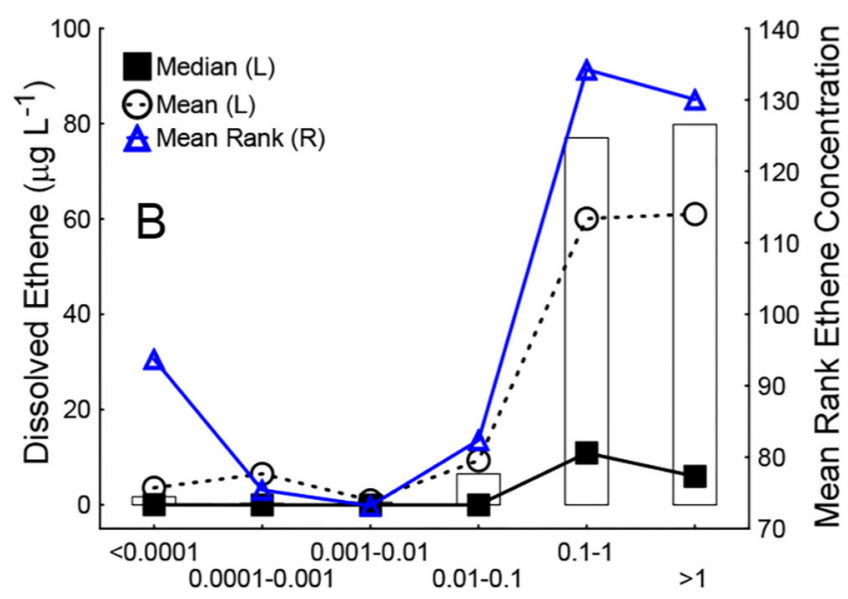

bvcA+vcrA/Total Bacterial 16S rRNA Gene Copies (\%)

Figure 2.

Dhc biomarker gene abundances normalized to total bacterial 16S rRNA gene abundances inform about ethene formation potential. Ethene concentrations were significantly greater in samples with (A) Dhc 16S rRNA gene and (B) VC RDase gene abundances greater than 1\% and $0.1 \%$ of the bacterial $16 \mathrm{~S}$ rRNA gene abundance, respectively. The Kruskal-Wallis $\mathrm{H}$ test was performed with ethene concentration as the dependent variable ( $y$ axis) and ranges of (A) percent Dhc/bacterial 16S rRNA gene abundance and (B) percent $b v c+v c r A$ /bacterial $16 \mathrm{~S}$ rRNA gene abundance as the independent, categorical factor ( $x$ axis). For each category (e.g., percent $D h c /$ bacterial $16 \mathrm{~S}$ rRNA gene abundance $>1 \%$ ), the median, mean, and mean rank of ethene concentration are shown. Boxes represent the interquartile range. The top and the bottom of each box represent the $25^{\text {th }}$ and the $75^{\text {th }}$ percentiles, respectively. KruskalWallis tests $[\mathrm{H}(k-1, N)]$ for nonparametric one-way ANOVA indicated significant differences in mean ranks of ethene concentrations with percent $D h c /$ bacterial 16S rRNA gene abundance $[\mathrm{H}(5, N=197)=39.0, p<0.05]$ and percent $b v c+v c r A /$ bacterial $16 \mathrm{~S}$ rRNA gene abundance $[\mathrm{H}(5, N=197)=25.8, p<0.05]$ as the independent variables. 

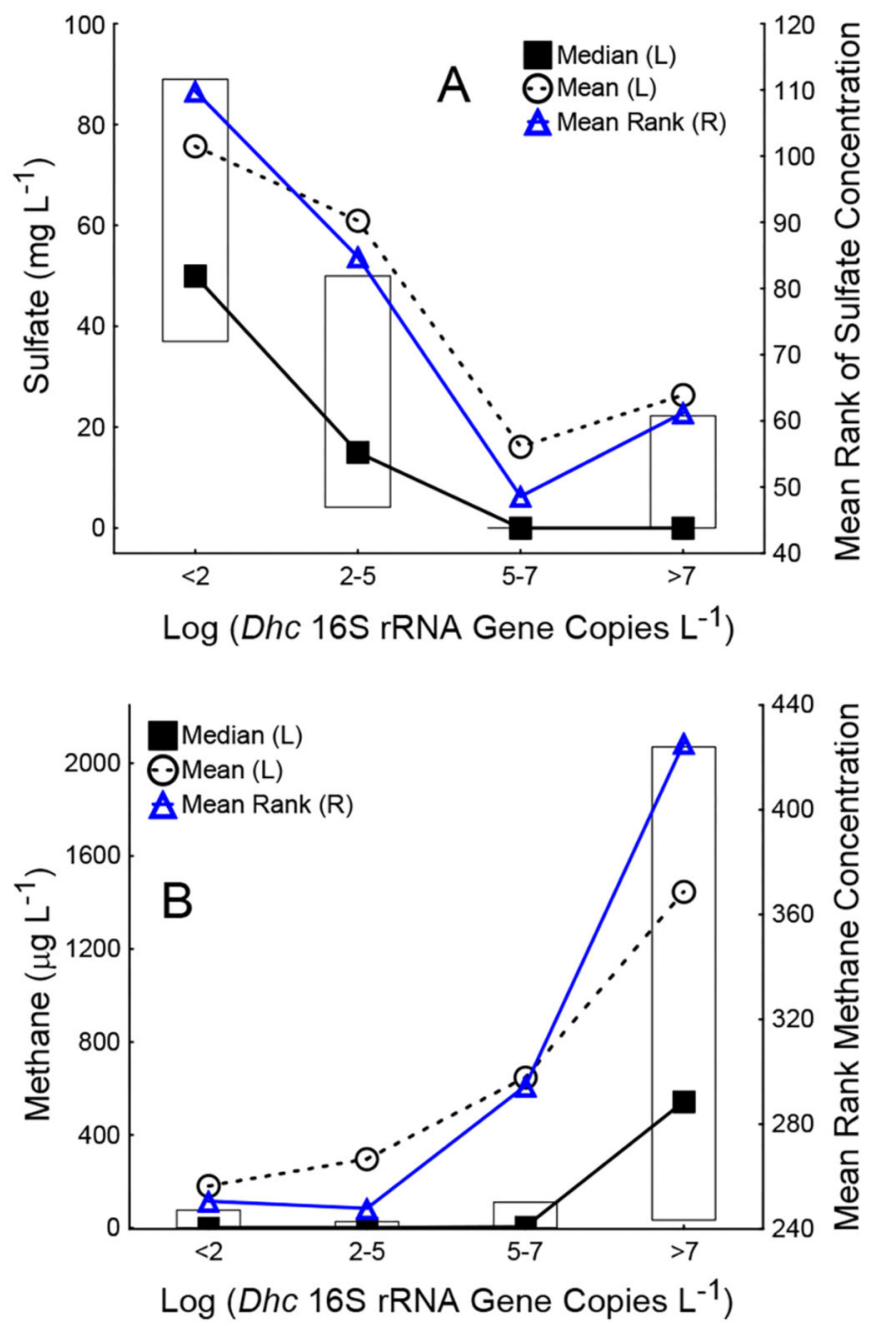

Figure 3.

Effect of geochemical conditions on Dhc abundance. (A) Sulfate concentrations were significantly lower in samples with $D h c$ abundances greater than $10^{5}$ copies $\mathrm{L}^{-1}$, and (B) $D h c$ abundances greater than $10^{7}$ copies $\mathrm{L}^{-1}$ correlated with elevated methane concentrations. The Kruskal-Wallis H test was performed with (A) sulfate concentration and (B) methane concentration as the dependent variables ( $y$ axis) and order of magnitude ranges of $\log D h c$ abundance as the independent, categorical factor ( $x$ axis). For each category (e.g., $\log$ Dhc 16S rRNA gene copies $\mathrm{L}^{-1}<2$ ), the median, mean, and mean rank of ethene concentration are shown. Only samples from sites undergoing biostimulation or bioaugmentation were considered for analysis with sulfate as the dependent variable. Due to the limited number of samples from biostimulation and bioaugmentation sites where methane was reported, all available data were included during analysis with methane as the dependent variable. Kruskal-Wallis tests $[\mathrm{H}(k-1, N)]$ for nonparametric one-way ANOVA indicated significant differences in mean ranks of sulfate $[\mathrm{H}(3, N=142)=40.9]$ and methane $[\mathrm{H}(3, N=554)=69.8]$ concentrations with $\log D h c$ abundance as the independent variable. 

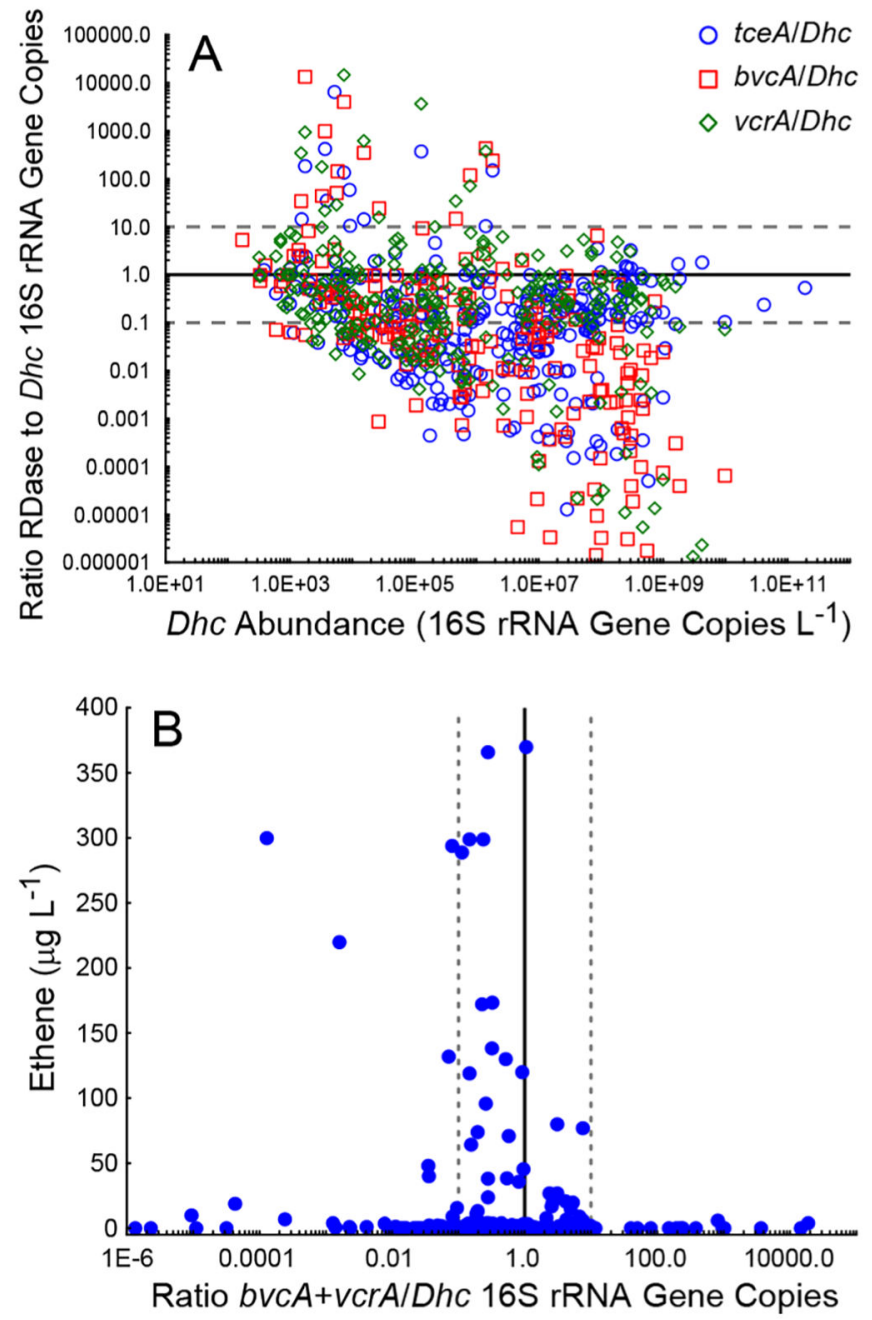

Figure 4.

Correlations between RDase gene and Dhc 16S rRNA gene abundances with detoxification potential. (A) Ratio of RDase to Dhc 16S rRNA gene copies. The solid black line indicates a 1:1 ratio of RDase to Dhc $16 \mathrm{~S}$ rRNA gene copies. Points above the dashed line are from the 19 groundwater samples where the abundance of RDase genes exceeded Dhc by 10-fold or greater. (B) Ethene concentration as a function of the ratio of the sum of VC RDase gene copies to $D h c 16 \mathrm{~S}$ rRNA gene copies $(b v c A+v c r A / D h c)$. The highest ethene concentrations were observed when the ratio of RDase to $D h c 16 \mathrm{~S}$ rRNA genes was near 1.0. The solid black line indicates that the sum of the RDase genes (i.e., $b v c A+v c r A$ ) equals the number of Dhc 16S rRNA genes. The dashed lines outline a 10-fold difference from a 1:1 ratio as an estimated maximum uncertainty associated with target gene quantification. 


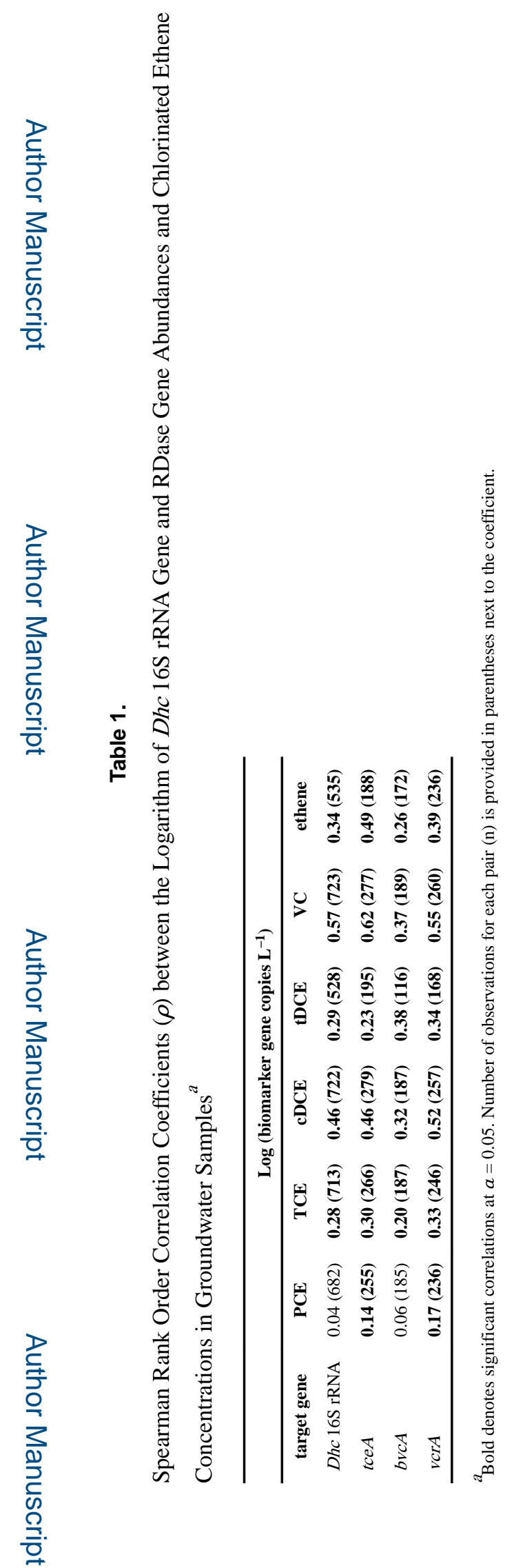

Environ Sci Technol. Author manuscript; available in PMC 2020 January 07. 


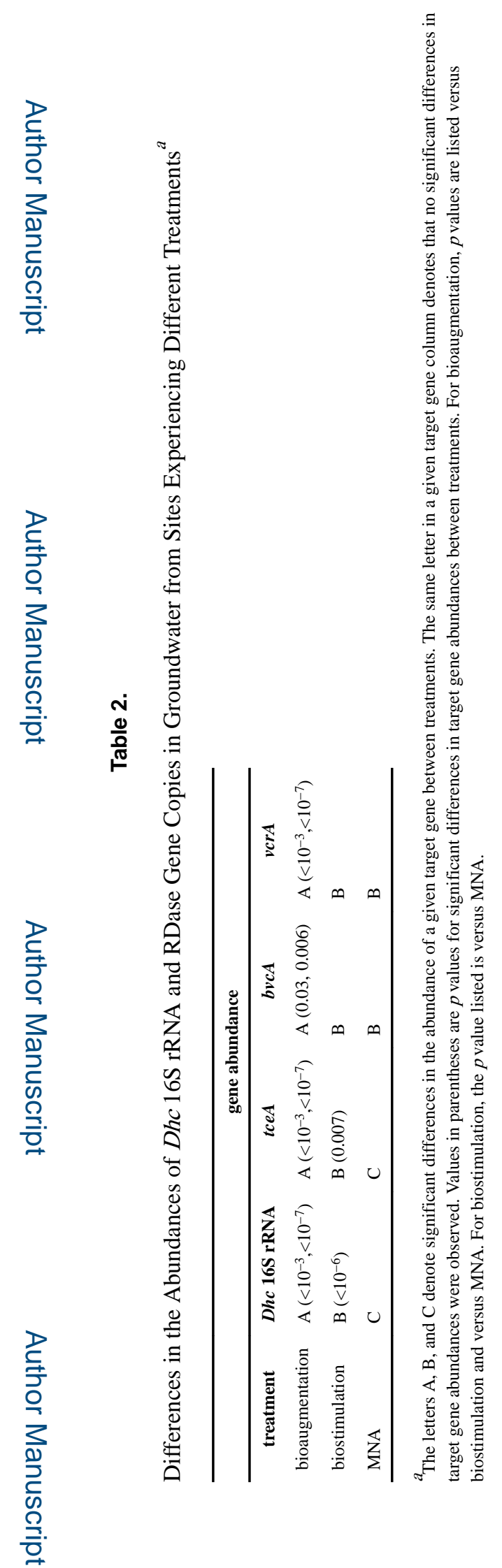

Environ Sci Technol. Author manuscript; available in PMC 2020 January 07. 